\section{A) Check for updates}

Cite this: Polym. Chem., 2018, 9 2336

Received 9th January 2018, Accepted 17th March 2018

DOI: $10.1039 / c 8 p y 00034 d$ rsc.li/polymers

\title{
Chemoenzymatic synthesis of polypeptides consisting of periodic di- and tri-peptide motifs similar to elastin $\uparrow$
}

\author{
Prashant G. Gudeangadi, ${ }^{a}$ Kousuke Tsuchiya, (D) *a Takamasa Sakai (D) b and \\ Keiji Numata iD *a
}

\begin{abstract}
Proline and valine exist in repetitive motifs in various structural proteins and play an important role in their physiological functions. Herein, we synthesized polypeptides that consist of di- and tri-peptide motifs containing proline and valine via chemoenzymatic polymerization. Di- and tri-peptide ethyl esters (ValGly-OEt, GlyProGly-OEt, and ValProGly-OEt) could be polymerized by papain, whereas proline and valine ethyl esters (Pro-OEt, Val-OEt) were inactive in chemoenzymatic polymerization because of their poor affinity for papain. The copolymer of ValProGly-OEt and ValGly-OEt being poly(ValProGly-coValGly), which is composed of a repetitive sequence of elastin, exhibited a temperature-dependent structural transition similar to tropoelastin. The post-polycondensation product of poly(ValProGly-co-ValGly) showed higher molecular weight and elastin-like thermal behaviors.
\end{abstract}

\section{Introduction}

Polypeptides are building blocks in various natural proteins. The chemical and biological properties of proteins depend on their amino acid sequence, referred to as their primary structure. According to the primary structure of proteins, their specific higher order structures are folded and formed to function. Due to their specific structures and functionality, they have been employed as biomaterials in various fields, including tissue engineering and biomedicine. ${ }^{1-7}$ Structural proteins such as silk, collagen, and elastin are mainly composed of a highly repetitive sequence in which short polypeptide motifs periodically replicate. These repetitive sequences assemble into higher order structures with excellent mechanical properties. $^{6,7}$ Structural proteins obtain their mechanical properties from certain important amino acids, such as proline in spider silk, collagen, and elastin. Proline exists in repetitive short peptide motifs in these structural proteins, such as glycine-proline-glycine (GlyProGly), in the major ampullate spidroin (MaSp) protein of spider silk ${ }^{8}$ and glycine-proline-hydroxyproline (GlyProHyp) in collagen. ${ }^{9}$ On the other hand, elastin contains valine-proline-glycine-valine-glycine (ValProGlyValGly)

\footnotetext{
${ }^{a}$ Enzyme Research Team, RIKEN Center for Sustainable Resource Science, 2-1 Hirosawa, Wako-shi, Saitama 351-0198, Japan.E-mail: keiji.numata@riken.jp, kosuke.tsuchiya@riken.jp

${ }^{b}$ Department of Bioengineering, School of Engineering, University of Tokyo,

7-3-1 Hongo, Bunkyo-ku, Tokyo 113-8656, Japan

$\dagger$ Electronic supplementary information (ESI) available: Scheme S1, Fig. S1-14, Tables S1-S3. See DOI: 10.1039/c8py00034d
}

in its hydrophobic region, and its high elastic properties arise from the tandem sequence of ValProGlyValGly. ${ }^{10}$ Both proline and valine are essential to realize such elasticity. ${ }^{11}$

Even though conventional solid phase peptide synthesis can be used for constructing precise target sequences, the tedious multistep reactions with several protection and deprotection steps restrict their large-scale production. ${ }^{12,13}$ Ringopening polymerization of amino acid $\mathrm{N}$-carboxyanhydrides (NCAs) can also be widely employed for the synthesis of polypeptides with precise control of molecular weight. This method is beneficial for the preparation of di- or tri-block polypeptides but has a poor sequence control. ${ }^{14}$

On the other hand, chemoenzymatic reactions have emerged as an advantageous method over other solutionbased syntheses because of their environmental benignity. These reactions are an atom-economical and facile approach that uses mild aqueous media and is scalable to industrial production. ${ }^{15}$ Using chemoenzymatic polymerization, we have developed various polypeptides, including not only homopolymers but also random copolymers containing several amino acid residues. ${ }^{16-19}$ Previously, we demonstrated that synthetic multiblock polypeptides mimicking spider dragline silk were successfully prepared by the post-polymerization of poly( $\mathrm{L}^{-}$ alanine) (polyAla) and poly(glycine-r-L-leucine) (poly(Gly- $r$ Leu)), which have primary structures similar to crystalline and amorphous motifs in the sequence of native spider silk proteins, respectively. ${ }^{20}$

Di- or tri-peptide esters are also available for use as monomers in chemoenzymatic polymerization, resulting in periodic primary structures. The protease-catalyzed polymerization of 
AlaGly or LysLeu ethyl ester was performed by Gross et al., and the resulting polypeptides possessed alternating sequences that are hardly accessible by conventional polypeptide synthesis in solution. ${ }^{21,22}$ Recently, we also demonstrated that even an unnatural amino acid such as 2-aminoisobutyric acid (Aib) can be polymerized using a tri-peptide ester in which Aib is incorporated with L-alanine. ${ }^{23}$ The resulting polypeptide possessed repetitive primary structures with AlaAibAla units. The periodic insertion of Aib units in the polyAla backbone could induce a substantial transition in the secondary structure from a $\beta$-strand to a helical conformation.

\section{Results and discussion}

\section{Chemoenzymatic copolymerization}

Herein, we synthesized tri-peptide ethyl esters where proline was sandwiched between amino acids with high affinity for papain. Valine was also polymerized using di-peptide or tripeptide ethyl esters (Scheme 1 and S1 $\dagger$ ). These di- and tripeptide motifs are frequently observed in the repetitive motifs of structural proteins, especially elastin. Therefore, the chemoenzymatic copolymerization of these monomers can afford polypeptide materials with elastin-mimicking amino acid sequences. The chemoenzymatic polymerization was performed using papain as a catalyst in $1 \mathrm{M}$ phosphate buffer solution (PBS) at pH 8.0 at $40{ }^{\circ} \mathrm{C}$; the results are tabulated in Table 1. In the case of L-proline methyl (Pro-OMe) and ethyl (Pro-OEt) esters, no precipitation was observed after $2 \mathrm{~h}$, unlike the polymerization of their hydrophobic analogues such as L-leucine and L-alanine esters (Run 1, 2). ${ }^{24,25}$ The inactivity of proline esters to papain-catalyzed polymerization may

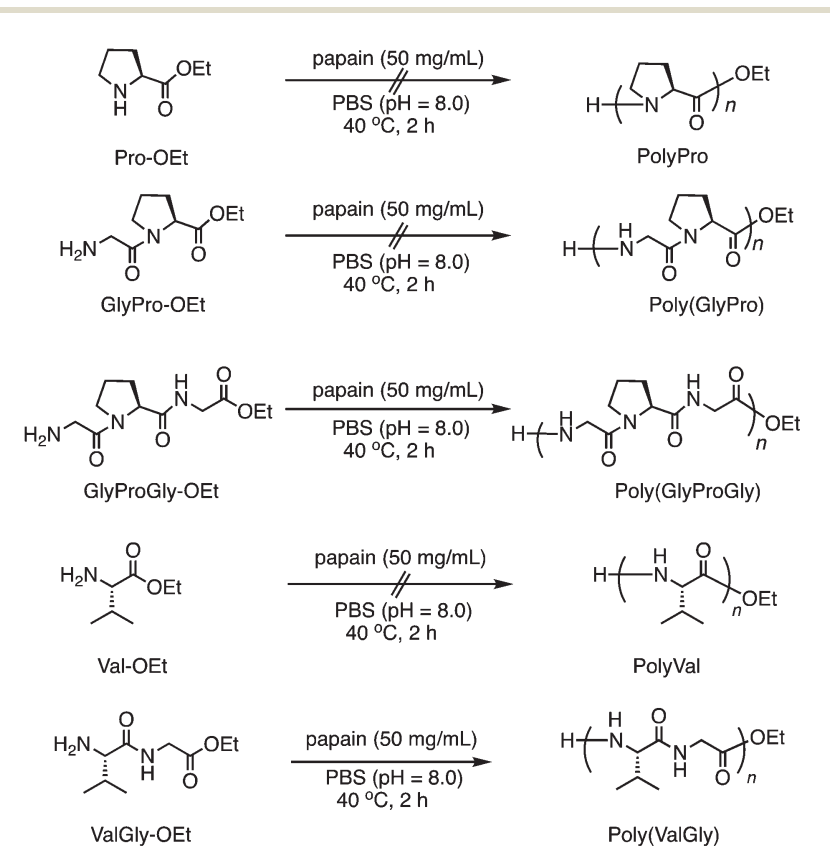

Scheme 1 Chemoenzymatic polymerization of Pro- and Val-containing monomers using papain.
Table 1 Chemoenzymatic polymerization of proline and valine containing monomers ${ }^{a}$

\begin{tabular}{lllll}
\hline Run & Monomer & Conc. (M) & Time (h) & Yield $^{b}(\%)$ \\
\hline 1 & Pro-OMe & 1.0 & 2 & 0 \\
2 & Pro-OEt & 1.0 & 2 & 0 \\
3 & GlyPro-OEt & 1.0 & 2 & 0 \\
4 & GlyPro-OEt/Gly-OEt & 1.0 & 2 & 0 \\
5 & GlyPro-OBn & 1.0 & 24 & 0 \\
6 & GlyPro-OBn/Gly-OBn & 0.001 & 2 & 0 \\
7 & GlyProGly-OEt & 1.0 & 2 & 31 \\
8 & Val-OEt & 1.0 & 2 & 0 \\
9 & Val-OEt & 0.5 & 12 & 0 \\
10 & Val-OEt & 0.001 & 12 & 0 \\
$11^{c}$ & Val-OEt & 1.0 & 2 & 0 \\
12 & ValGly-OEt & 1.0 & 2 & 31 \\
13 & ValProGly-OEt & 1.0 & 2 & 1 \\
$14^{d}$ & GlyProGly-OEt/ValGly-OEt & 1.0 & 2 & 30 \\
$15^{d}$ & ValProGly-OEt/ValGly-OEt & 1.0 & 2 & 28
\end{tabular}

${ }^{a}$ Polymerization was carried out using monomer ( $\mathrm{HCl}$ salt) and papain $\left(50 \mathrm{mg} \mathrm{mL}{ }^{-1}\right)$ in phosphate buffer $(1 \mathrm{M}, \mathrm{pH} 8.0)$ at $40{ }^{\circ} \mathrm{C}$ for $2-24 \mathrm{~h}$. ${ }^{b}$ Precipitation was collected by centrifugation, washed with water, and lyophilized. ${ }^{c}$ Carbonate buffer $(1 \mathrm{M}, \mathrm{pH} 10)$ was used for the reaction. ${ }^{d}$ Molar ratio was $1 / 1$.

be related to the inability of papain to recognize proline residues, which possess a bulky cyclic structure. Because it was found that modification of Aib with protease-recognizable residues can mitigate a mismatch with the substrate pocket in papain, ${ }^{23}$ the di-peptides Gly-L-Pro ethyl ester (GlyPro-OEt) and benzyl ester (GlyPro-OBn) were synthesized. The homopolymerization of GlyPro-OEt (Run 3) and its copolymerization using Gly-OEt (Run 4) were evaluated in the papain-catalyzed polymerization, but no precipitation was observed in either case. Prolonging the polymerization time (Run 5) and performing the copolymerization at a lower concentration (Run 6) for GlyPro-OBn provided the same results. Hence, we designed and synthesized novel tri-peptide ester monomers in which proline was sandwiched with natural amino acids, namely, Gly-L-Pro-Gly ethyl ester (GlyProGly-OEt) and L-Val-L-Pro-Gly ethyl ester (ValProGly-OEt), as $\mathrm{HCl}$ salts by the traditional solution method. ${ }^{26}$ The chemoenzymatic polymerization of GlyProGly-OEt afforded a precipitate at 31\% yield at a feed concentration of $1.0 \mathrm{M}$ (Run 7), which was significantly different from previous results (Run 1-6). Thus, we concluded that the Gly units at both sides of proline is a key factor in papain recognition in this chemoenzymatic polymerization with proline residues.

As another key amino acid residue in elastin, Val-OEt was also tested in the papain-catalyzed polymerization at different feed concentrations (Run 8-10). Even at a lower concentration with prolonged reaction time (Run 10), the polypeptide could not be obtained as a precipitate. Carbonate buffer solution ( $\mathrm{pH}$ 10) was also employed to promote the polymerization, which also did not afford a precipitate (Run 11). In contrast, the di-peptide L-Val-Gly ethyl ester (ValGly-OEt) could be polymerized at a feed concentration of $1.0 \mathrm{M}$ to afford a precipitate (Run 12). These results also indicated that the Gly unit is a key factor in papain recognition in this chemoenzymatic polymer- 
ization. The homopolymerization of ValProGly-OEt, which was highly hygroscopic, afforded very little precipitation under similar conditions to ValGly-OEt (Run 13). This was due to the higher solubilities of monomer and polymer in the buffer.

Furthermore, we carried out the copolymerization of GlyProGly-OEt/ValGly-OEt (Run 14) and ValProGly-OEt/ValGlyOEt (Run 15) (Scheme 2a). The polymerization of GlyProGlyOEt and ValGly-OEt afforded a precipitate in $30 \%$ yield. The copolymerization of ValProGly-OEt with ValGly-OEt also afforded a precipitate in $28 \%$ yield.

To confirm the role of enzyme in the polymerization reaction, blank reactions without enzymes were performed (Table S1 $\dagger$ ), according to the previous literature. ${ }^{27-29}$ The blank reactions for GlyProGly-OEt and ValGly-OEt were carried out in the absence of papain. The polymerization reaction was performed using $1 \mathrm{M}$ PBS at $\mathrm{pH} 8.0$ at $40{ }^{\circ} \mathrm{C}$ for $2 \mathrm{~h}$. No polymerized product was detected by ${ }^{1} \mathrm{H}$ nuclear magnetic resonance ( ${ }^{1} \mathrm{H}$ NMR) spectroscopy (Fig. S1†), meaning that the reaction didn't proceed without papain. The copolymerization of GlyProGly-OEt/ValGly-OEt and ValProGly-OEt/ValGly-OEt was also carried out in the absence of papain, that resulted in no polymerized products based on ${ }^{1} \mathrm{H}$ NMR measurements (Fig. S2 $\dagger$ ). Thus, we confirmed that papain acts as a catalyst and drives the polymerization reaction.

\section{Chemical structure analyses by MALDI-TOF mass and NMR spectroscopy}

The chemical structures of these products were confirmed by matrix-assisted laser desorption/ionization time-of-flight mass spectrometry (MALDI-TOF MS) and ${ }^{1} \mathrm{H}$ NMR spectroscopy. In its MALDI-TOF MS spectrum (Fig. 1a), poly(GlyProGly) exhibited two series of products up to the monomer with an ethyl ester or carboxylic acid at the C-terminal end. The series of peaks with an interval of $\mathrm{m} / \mathrm{z} 211$, which corresponds to the GlyProGly tri-peptide unit, indicates the successful polymerization of GlyProGly-OEt. The polymer showed a relatively higher degree of polymerization than the values of previously reported polymer obtained by chemoenzymatic polymerization. ${ }^{30,31}$ The molar mass of poly(GlyProGly) was in the range from 400 to $2000 \mathrm{Da}$. In the MALDI-TOF MS spectrum of ValGly-OEt (Fig. 1a), two series of peaks derived from poly(ValGly) up to

$$
\text { a) }
$$

Scheme 2 (a) Chemoenzymatic copolymerization of Pro- and Val-containing di- and tri-peptides using papain and (b) post-polycondensation of poly(ValProGly-co-ValGly). a)

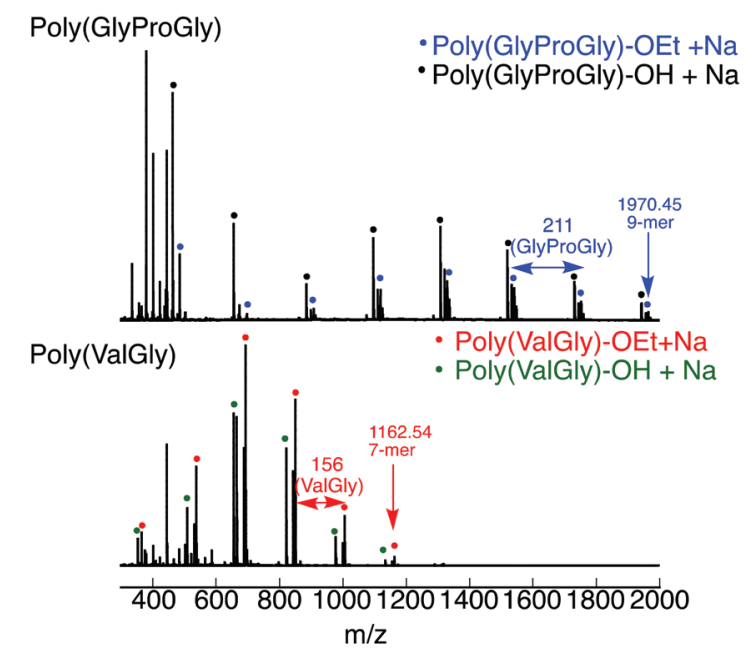

b)

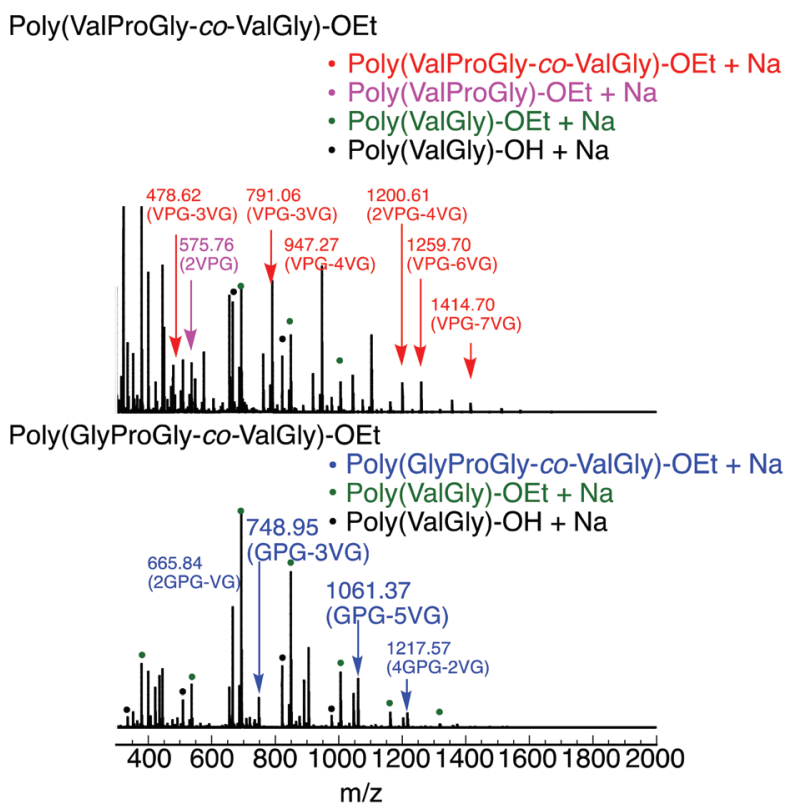

Fig. 1 MALDI-TOF mass spectra of (a) poly(GlyProGly) and poly(ValGly) and (b) poly(ValProGly-co-ValGly) and poly(GlyProGly-co-ValGly) prepared by papain-catalyzed polymerization.

the heptamer with a C-terminal ethyl ester or carboxylic acid were detected. The copolymer synthesized from ValProGly-OEt and ValGly-OEt, poly(ValProGly-co-ValGly), afforded peaks with various combinations of di- and tri-peptide units. Molar masses assignable to ValProGly/ValGly units with different ratios were observed, indicating the successful incorporation of both units in the polypeptide chain (Fig. 1b). The copolymer from GlyProGly-OEt and ValGly-OEt, poly(GlyProGly-co-ValGly), also afforded several peaks corresponding to the molar mass of GlyProGly/ValGly units with different ratios (Fig. 1b). In addition to the peaks of poly(GlyProGly-co-ValGly), the peaks derived from poly(ValGly) with ethyl ester and carboxylic acid 
groups at the C-terminal end were also detected in both cases. This could be due to the high reactivity of the di-peptide ValGly-OEt compared to the tri-peptide GlyProGly-OEt.

The tri-peptide esters GlyProGly-OEt and ValProGly-OEt and di-peptide ester ValGly-OEt were characterized by both ${ }^{1} \mathrm{H}$ and ${ }^{13} \mathrm{C}$ NMR spectroscopy. The proline peaks at approximately 1.75-2.25 ppm indicate the successful incorporation of proline in the tri-peptide. The $-\mathrm{CH}_{3}$ peak at approximately $1.25 \mathrm{ppm}$, along with the $-\mathrm{CH}_{2}$ peak at approximately $4.1 \mathrm{ppm}$ of the ester group of the glycine unit, indicates the formation of the tri-peptide. The ${ }^{1} \mathrm{H}$ NMR spectrum of ValProGly-OEt has a relatively similar spectral pattern to that of GlyProGly-OEt. The peaks at approximately $1 \mathrm{ppm}$ are assigned to the two $-\mathrm{CH}_{3}$ groups of valine, along with the peak for the methine proton at approximately $2.4 \mathrm{ppm}$. The ${ }^{1} \mathrm{H}$ NMR spectrum of ValGlyOEt shows peaks derived from both valine and glycine. The peak at $2.2 \mathrm{ppm}$ of the methine proton and doublet of doublets for two $-\mathrm{CH}_{3}$ groups indicate the presence of valine. The triplet peak at approximately $1.2 \mathrm{ppm}$ and quartet at approximately $4.2 \mathrm{ppm}$ for the ester of glycine, along with the glycine peaks, indicate the formation of the di- and tri-peptides containing both Val and Gly (Fig. S3, S5, and S7 ). In the ${ }^{13} \mathrm{C}$ NMR spectrum, the 3 carbonyl signals for the tri-peptide unit and 2 carbonyl signals for the di-peptide unit were observed, indicating the successful formation of both the tri- and di-peptide esters (Fig. S4, S6, and S8 $\dagger$ ). Fig. 2 shows the ${ }^{1} \mathrm{H}$ NMR spectra of poly(GlyProGly), poly(ValGly) (Fig. 2a), poly(ValProGly-coValGly) and poly(GlyProGly-co-ValGly) (Fig. 2b). The ${ }^{1} \mathrm{H}$ NMR spectrum of poly(GlyProGly) shows the characteristic signals of the proline unit at 1.75-2.25 ppm, indicating the formation of the tri-peptide and its polymers. The ${ }^{1} \mathrm{H}$ NMR spectrum of poly(ValGly-OEt) exhibits the characteristic signals derived from the valine unit at $0.75-1.00 \mathrm{ppm}$. The ${ }^{1} \mathrm{H}$ NMR spectrum of poly(ValProGly-co-ValGly) shows the peaks derived from both the proline and valine units, indicating successful incorporation of both ValProGly and ValGly units. Finally, the ${ }^{1} \mathrm{H}$ NMR spectrum of poly(GlyProGly-co-ValGly) also shows protons derived from both monomers, indicating the incorporation of both units in the polypeptide chain.

\section{Secondary structure characterization by CD spectroscopy}

It is well known that the ValProGly triad is responsible for the $\beta$-turn confirmation. ${ }^{11}$ To examine the effect of ValGly on the resulting copolymers, we evaluated the secondary structures of the polypeptides in solution by circular dichroism (CD) spectroscopic analysis. All polypeptides were soluble in water except poly(GlyProGly), which was found to be insoluble. Thus, the CD spectra of the polypeptides were analyzed in 2,2,2-trifluoroethanol (1 $\mathrm{mM}$, containing $0.1 \%$ trifluoroacetic acid) and are displayed in Fig. S9. $\uparrow$ The contents of the secondary structures were calculated using the DichroWeb online CD analysis server and are tabulated in Table S2. $\uparrow$ The CD spectrum of poly(GlyProGly) showed a positive peak centered at approximately $205 \mathrm{~nm}$ with a monotonic decrease at lower wavelengths, whereas the CD spectrum of poly(ValGly) showed a negative Cotton effect with negative and positive peaks at a)

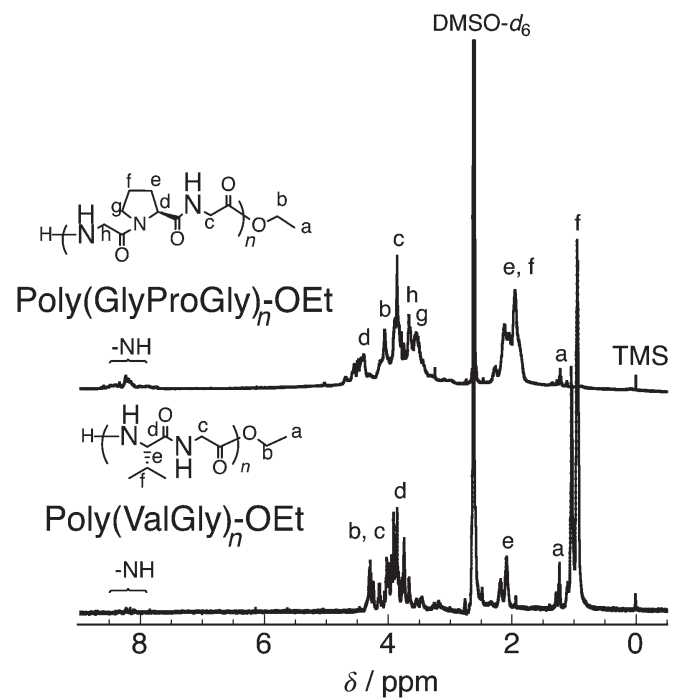

b)

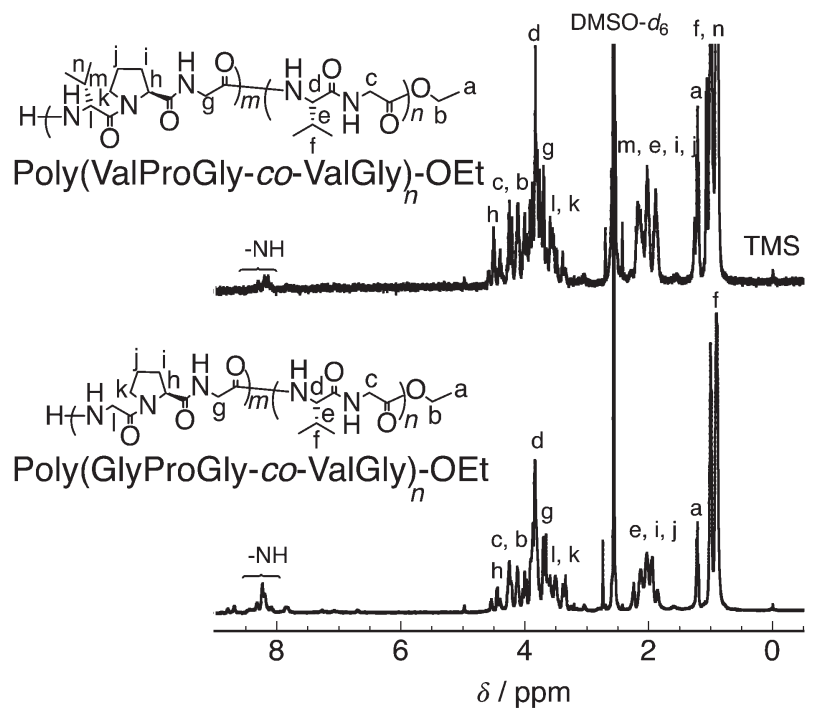

Fig. $2{ }^{1} \mathrm{H}$ NMR spectra of (a) poly(GlyProGly) and poly(ValGly) and (b) poly(ValProGly-co-ValGly) and poly(GlyProGly-co-ValGly), in DMSO- $d_{6} /$ TFA- $d(5 / 1)$.

approximately 215 and $197 \mathrm{~nm}$, respectively. Poly(GlyProGly) was likely to adopt a more disordered structure than poly (ValGly), which predominantly showed $\beta$-strand propensity. This was due to the bent structure of the proline units in poly (GlyProGly), as seen in the amorphous sequence of spider silk proteins showing an elastic nature. ${ }^{8}$ The CD spectra of poly (GlyProGly-co-ValGly) and poly(ValProGly-co-ValGly) also showed a negative Cotton effect. Poly(GlyProGly-co-ValGly) adopted more $\beta$-strand structure than poly(GlyProGly). This result emphasizes that the ValGly unit is essential for inducing $\beta$-strands in the polypeptide chain. On the other hand, poly (ValProGly-co-ValGly) adopted a rather unordered structure in 2,2,2-trifluoroethanol.

The secondary structure of tropoelastin (a soluble precursor of elastin) is known to vary in response to hydrophobic interactions at different temperatures, which, above a lower critical 
solution temperature (LCST), cause insoluble aggregation (coacervation). ${ }^{32}$ The CD spectra of poly(ValProGly-co-ValGly), which possesses a sequence similar to the repetitive motif of elastin, were analyzed in water $(1 \mathrm{mM})$ at different temperatures between 10 and $80{ }^{\circ} \mathrm{C}$ to examine the thermal behavior of the polypeptide. Fig. 3 shows CD profiles in a second heating and cooling cycle to eliminate the thermal history of the sample. The secondary structure calculated using DichroWeb is summarized in Table S3. $\uparrow$ The initial secondary structure at $20{ }^{\circ} \mathrm{C}$ was dominated by a $\beta$-strand structure $(6.0 \%$ helix, 36.5\% $\beta$-strand, $21.5 \% \beta$-turn, and $36.0 \%$ unordered), which is largely consistent with the reported secondary structure of tropoelastin (3\% helix, $41 \% \beta$-strand, $21 \% \beta$-turn, and $33 \%$ unordered). ${ }^{32}$ As the temperature increased from 10 to $80^{\circ} \mathrm{C}$, the CD spectra showed a remarkable change. Both positive and negative bands increased in intensity. The helical structure was more preferred at higher temperature $(9.3 \%$ helix, $37 \% \beta$-strand, $22 \% \beta$-turn, and $31 \%$ unordered at $80^{\circ} \mathrm{C}$ ), and the percentage of unordered structure decreased. This behavior was also observed for artificial elastin analogues. ${ }^{32-34}$ When the sample was cooled from 80 to $10{ }^{\circ} \mathrm{C}$, the unordered content increased with reversible decrease in the helical content. This clearly shows that poly(ValProGly-co-ValGly) undergoes a structural transition similar to natural elastin at elevated temperatures. Unfortunately, a clouding point was not observed for poly(ValProGly-co-ValGly) in water. Because the molecular weight of the obtained poly(ValProGly-co-ValGly) is low (below $1500 \mathrm{Da}$ ), the structural change is assumed to be so weak that aggregation cannot be induced by hydrophobic interactions. On the other hand, the CD spectra of poly (GlyProGly-co-ValGly) in water exhibit only a slight change at different temperatures (Fig. S10 and S11 ${ }^{\dagger}$ ). Therefore, both ValProGly and ValGly sequence units are essential for forming an elastin-like secondary structure.

\section{Post-polycondensation of poly(ValProGly-co-ValGly)}

According to the previous study, ${ }^{20}$ we performed a post-polycondensation reaction of poly(ValProGly-co-ValGly) in the presence of polyphosphoric acid as a condensing agent at elevated temperature to obtain a higher molecular weight (Scheme 2b). The chain elongation was successfully achieved to afford the
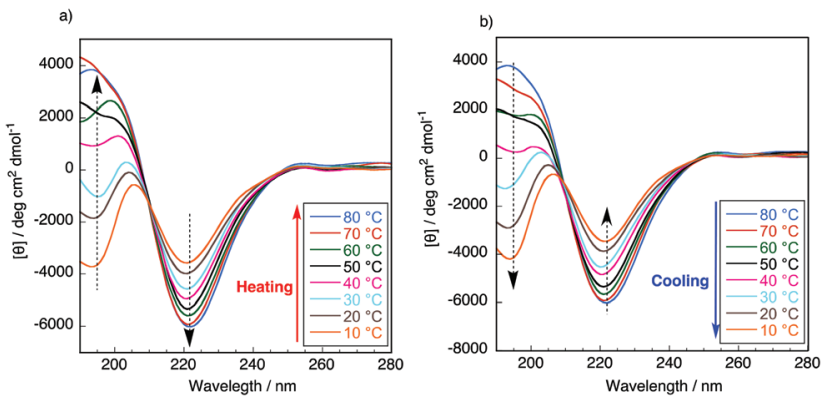

Fig. 3 CD spectra of poly(ValProGly-co-ValGly) in water in the second (a) heating and (b) cooling cycle at different temperatures between 10 and $80^{\circ} \mathrm{C}$. The concentration of the polypeptide was $1 \mathrm{mM}$. post-polycondensation product, PP-poly(ValProGly-co-ValGly), and the obtained polymer was analyzed by ${ }^{1} \mathrm{H}$ NMR spectroscopy and gel permeation chromatography (GPC). The number- and weight-average molecular weights $\left(M_{\mathrm{n}}\right.$ and $\left.M_{\mathrm{w}}\right)$ and molecular weight distribution $\left(M_{\mathrm{w}} / M_{\mathrm{n}}\right)$ estimated by the GPC profile were 4900, 11000 , and 1.81, respectively (Fig. S12a †). The molecular weights were determined by using polystyrene standards (Fig. S12b $\dagger$ ). In the case when protein molecular weight standards are used to determine the molecular weight (Fig. S12c $\dagger$ ), the molecular weight of PP-poly (ValProGly-co-ValGly) is slightly higher. Thus, the polystyrene standards could be applicable to determine the molecular weight of the polypeptide by GPC. Unfortunately, the obtained polymer showed poor solubility in water and common organic solvents, except for $N$-methyl-2-pyrrolidone (NMP) and TFA. The ${ }^{1} \mathrm{H}$ NMR spectrum of the sample was analyzed in TFA- $d$ and compared with that of the prepolymer, poly(ValProGly-coValGly), obtained in the same solvent (Fig. 4). The ${ }^{1} \mathrm{H}$ NMR spectrum showed broad peaks, clearly indicating the higher molecular weight of the polymer. The peaks corresponding to both valine and proline residues are distinguishable. However, the peaks of proline at approximately 2.0-2.6 ppm overlapped with peaks of glycine at approximately 4.0-5.0 $\mathrm{ppm}$. This could be attributed to the longer polypeptide chain and the change in the secondary structure of the obtained PP-poly(ValProGlyco-ValGly).

\section{Thermal properties of PP-poly(ValProGly-co-ValGly)}

To characterize the thermal behavior of PP-poly(ValProGly-coValGly), we performed thermal gravimetric analysis (TGA) and differential scanning calorimetry (DSC) measurements. The TGA profiles of poly(ValProGly-co-ValGly) before and after postpolycondensation showed a $5 \%$ degradation temperature $\left(T_{\mathrm{d} 5}\right)$ at $190{ }^{\circ} \mathrm{C}$ regardless of the molecular weight (Fig. 5a). The
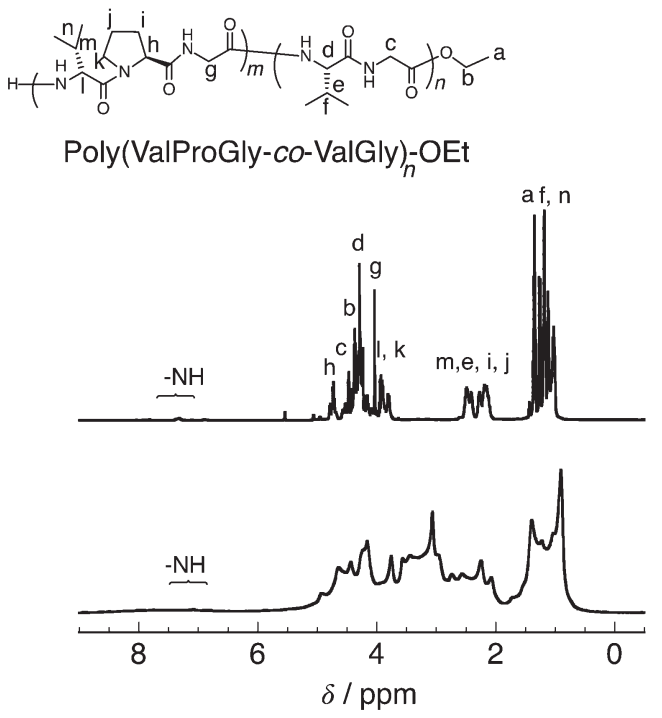

Fig. $4{ }^{1} \mathrm{H} \quad$ NMR of poly(ValProGly-co-ValGly) (top) and PP-poly (ValProGly-co-ValGly) (bottom) in TFA-d. 

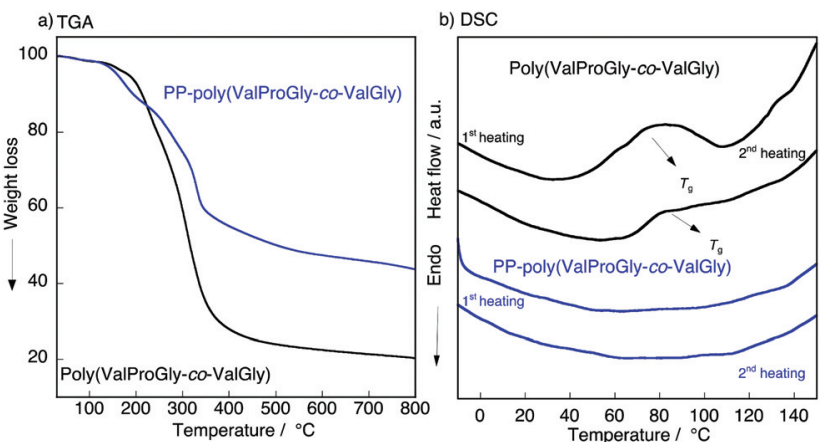

Fig. 5 (a) TGA, (b) DSC plot of the poly(ValProGly-co-ValGly) and PPpoly(ValProGly-co-ValGly) at $20^{\circ} \mathrm{C} \mathrm{min}^{-1}$.

thermal stability and degradation behavior of PP-poly (ValProGly-co-ValGly) were obviously improved and changed by increasing the molecular weight. The DSC profiles of the first and second heating scans are shown in Fig. 5b. The poly (ValProGly-co-ValGly) prepolymer clearly showed a glass transition temperature $\left(T_{\mathrm{g}}\right)$ at approximately $80{ }^{\circ} \mathrm{C}$. This glass transition was reproduced even in the second heating cycle. This revealed that poly(ValProGly-co-ValGly) is dominated by amorphous structures. On the other hand, PP-poly(ValProGly-coValGly) showed no $T_{\mathrm{g}}$ in either the first or second heating scans. This indicated that the increase in molecular weight restricts the polymer chain movement, which caused the $T_{\mathrm{g}}$ to shift to a higher temperature. The $T_{\mathrm{g}}$ of PP-poly(ValProGly-coValGly) might overlap with thermal degradation, since the $T_{\mathrm{g}}$ of dehydrated elastin ranges from 190 to $200{ }^{\circ} \mathrm{C} .{ }^{35,36}$ To detect the $T_{\mathrm{g}}$ of PP-poly(ValProGly-co-ValGly), we changed the heating and cooling rates at $10{ }^{\circ} \mathrm{C} \mathrm{min}^{-1}$ (Fig. S13†). However, the $T_{\mathrm{g}}$ of PP-poly(ValProGly-co-ValGly) was not detected. The storage and loss moduli of PP-poly(ValProGly-co-ValGly) were characterized at different temperatures up to $120{ }^{\circ} \mathrm{C}$ (Fig. S14 $\dagger$ ). The storage and loss moduli of PP-poly(ValProGlyco-ValGly) at $30^{\circ} \mathrm{C}$ indicate that the resultant polymer was relatively elastic. In addition, the elastin-like polymer became more elastic and softer at $50^{\circ} \mathrm{C}$.

\section{Secondary structures of PP-poly(ValProGly-co-ValGly)}

The structure of poly(ValProGly-co-ValGly) was characterized by FT-IR spectroscopy before and after post-polycondensation, and the amide region of the IR spectra is shown in Fig. 6. After post-polycondensation, a peak derived from the terminal ester group at $1750 \mathrm{~cm}^{-1}$ almost disappeared. This observation indicates that PP-poly(ValProGly-co-ValGly) has fewer terminal ester groups than the poly(ValProGly-co-ValGly) prepolymer as a result of the increase in molecular weight. In the amide I region, the sharp peak derived from the carbonyl group of the $\beta$-sheet structures at $1630 \mathrm{~cm}^{-1}$ decreased after the post-polycondensation reaction, and the amide I band was relatively broadened. In addition, PP-poly(ValProGly-co-ValGly) showed a slight shift in the amide II peak and a decrease in the amide III peak. This difference in IR spectra indicated that the post-polycondensation reaction induced disordered secondary structures.

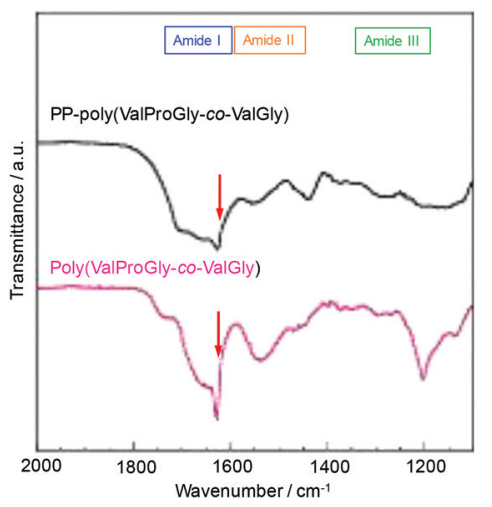

Fig. 6 IR spectra of PP-poly(ValProGly-co-ValGly) and poly(ValProGlyco-ValGly) expanded region from 1100 to $2000 \mathrm{~cm}^{-1}$.

\section{Conclusions}

In conclusion, we successfully polymerized di- and tri-peptide esters including key amino acids in elastin, namely, proline and valine, via papain-catalyzed polymerization. The modification of proline and valine, which are unfavorable substrates of papain, with a glycine unit allowed us to obtain polypeptides containing repetitive motifs similar to elastin. The copolymer poly(ValProGly-co-ValGly) with a sequence mimicking the highly repetitive sequence of elastin, ValProGlyValGly, was also synthesized. CD spectroscopic analysis revealed that poly (ValProGly-co-ValGly) exhibited a structural transition similar to tropoelastin. The chain elongation of poly(ValProGly-coValGly) was achieved by post-polycondensation. The higher-molecular-weight polymer obtained, PP-poly(ValProGly-co-ValGly), showed changes in secondary structure and thermal properties. The $T_{\mathrm{g}}$ of PP-poly(ValProGly-co-ValGly) might be shifted to higher temperature compared to that of poly(ValProGly-co-ValGly), similar to elastin. ${ }^{34}$ This work mirrors the syntheses of important natural structural proteins such as elastin, which could be used as structural materials in the future. This chemoenzymatic synthesis of polypeptides with periodic sequences will open the door for a new "eco-friendly synthesis" of polypeptide materials mimicking structural proteins.

\section{Experimental}

\section{Materials}

Papain was purchased from Wako Pure Chemical Industries, Ltd (Osaka, Japan) and used as received. The activity was approximately $0.5 \mathrm{U} \mathrm{g}^{-1}$, where one unit is defined as the amount of enzyme needed to hydrolyze $1 \mathrm{mmol}$ of $N$-benzoylDL-arginine $p$-nitroanilide per minute at $\mathrm{pH} 7.5$ and $25{ }^{\circ} \mathrm{C}$. $N$-Methyl-2-pyrrolidone (NMP) and $N, N$-dimethylacetamide (DMAc) were dried over $4 \AA$ molecular sieves. Diethyl ether and triethylamine were dried over $4 \AA$ molecular sieves and stored under a nitrogen atmosphere. All the other reagents were used as received without any purification unless otherwise noted. 


\section{Measurements}

${ }^{1} \mathrm{H}$ and ${ }^{13} \mathrm{C}$ nuclear magnetic resonance (NMR) spectra were recorded on a Varian NMR System 500 instrument (Varian Medical Systems, Palo Alto, CA) at $25{ }^{\circ} \mathrm{C}$ and at a frequency of $500 \mathrm{MHz}$. Dimethylsulfoxide- $d_{6}\left(\mathrm{DMSO}-d_{6}\right)$ with trifluoroacetic acid- $d$ (TFA- $d$ ) (5/1 in volume) was used as the solvent for the polypeptides with tetramethylsilane as the internal standard. Matrix-assisted laser desorption/ionization time-of-flight (MALDI TOF) mass spectrometry analysis was conducted using an ultrafleXtreme MALDI-TOF spectrophotometer (Bruker Daltonics, Billerica, MA) operating in a reflection mode at an accelerating voltage of $15 \mathrm{kV}$. The sample was dissolved in water/acetonitrile $\left(0.8 \mathrm{mg} \mathrm{mL} \mathrm{m}^{-1}\right)$ containing $0.1 \%$ TFA, mixed with a solution of $\alpha$-cyano-4-hydroxycinnamic acid (CHCA) in water/acetonitrile $\left(10 \mathrm{mg} \mathrm{mL}^{-1}\right)$, and deposited on an MTP 384 ground steel BC target plate. Circular dichroism (CD) spectroscopic analysis was conducted using a Jasco J-820 CD spectropolarimeter (JASCO, Tokyo, Japan). Measurements were conducted on polypeptide solutions (1 mM) in 2,2,2-trifluoroethanol (TFE) using a quartz cuvette with a $0.1 \mathrm{~cm}$ path length. Each spectrum represents the average of 10 scans from 190 to $290 \mathrm{~nm}$ with a resolution of $1 \mathrm{~nm}$ obtained at $200 \mathrm{~nm} \mathrm{~min}{ }^{-1}$ with a bandwidth of $1 \mathrm{~nm}$. The CD analysis at different temperatures was carried out by heating the sample from $10^{\circ} \mathrm{C}$ to $80^{\circ} \mathrm{C}$ with an increase of $10^{\circ} \mathrm{C}$ for each measurement. The sample was cooled from $80^{\circ} \mathrm{C}$ to $10^{\circ} \mathrm{C}$ by decreasing by $10^{\circ} \mathrm{C}$ for each measurement. Gel permeation chromatography (GPC) was performed on a JASCO HPLC system (PU-2086, DG2080-54, AS-2057, CO-2065; JASCO, Tokyo, Japan) with a Shodex KD-804 column (Showa Denko K. K., Tokyo, Japan) and a UV detector (UV-2075). Measurements were carried out on polypeptide samples $\left(2 \mathrm{mg} \mathrm{mL}^{-1}\right)$ eluted with NMP containing $10 \mathrm{mM}$ of lithium bromide at a flow rate of $1.0 \mathrm{~mL} \mathrm{~min}^{-1}$. The number$\left(M_{\mathrm{n}}\right)$ and weight-average molecular weights $\left(M_{\mathrm{w}}\right)$ and the molecular weight distribution $\left(M_{\mathrm{w}} / M_{\mathrm{n}}\right)$ were estimated using polystyrene standards of the following molecular weights: $1.32 \times$ $10^{3}, 3.25 \times 10^{3}, 1.01 \times 10^{4}, 2.85 \times 10^{4}, 6.60 \times 10^{4}$, and $1.56 \times$ $10^{5}$. Conalbumin from chicken egg white $\left(7.5 \times 10^{4} \mathrm{Da}\right)$, ovalbumin from hen egg $\left(4.3 \times 10^{4} \mathrm{Da}\right)$, Ribonuclease A from bovine pancreas $\left(1.37 \times 10^{4} \mathrm{Da}\right)$, and aprotinin from bovine lung $\left(6.5 \times 10^{3} \mathrm{Da}\right)$ were used for comparison between proteins and polystyrenes regarding elution time. The protein molecular weight standards were chosen from the Gel filtration calibration kit LMW (GE Healthcare, Chicago, USA). The infrared (IR) spectra of the samples were recorded by an IRPrestige-21 Fourier transform infrared spectrophotometer (Shimadzu Corporation, Kyoto, Japan) with a MIRacle A single reflection ATR unit using a Ge prism. DSC measurements were conducted by using a DSC (PerkinElmer, MA, USA). The polymer sample of 3-5 $\mathrm{mg}$ was weighed and sealed in an aluminum pan, which was heated and cooled at $20^{\circ} \mathrm{C} \mathrm{min}^{-1}$ from $-10{ }^{\circ} \mathrm{C}$ to $150{ }^{\circ} \mathrm{C}$ under a nitrogen atmosphere. The device was calibrated with an empty cell to establish a baseline and with indium to characterize the heat flow and temperature of the system. For the rheological analysis, powder samples were set in a rheometer (MCR302; Anton Paar, Austria) under a dry nitrogen gas flow. The measurement limit of the rheometer was approximately $0.1 \mathrm{~Pa}$. The storage modulus $\left(G^{\prime}\right)$ and the loss modulus $\left(G^{\prime \prime}\right)$ were measured by heating the sample from $30{ }^{\circ} \mathrm{C}$ to $120{ }^{\circ} \mathrm{C}$ with an increase of $10{ }^{\circ} \mathrm{C}$ for each data point. The strain and frequency were $1 \%$ and $1 \mathrm{~Hz}$, respectively. Measurements were performed at least three times for one data point.

\section{Synthetic procedures}

Synthesis of ProGly-OEt HCl salt. The proline (Pro)-containing di-peptide ProGly-OEt was synthesized via a modified conventional solution method according to a previously reported procedure. $^{23}$ To a flask equipped with an addition funnel and a stir bar, $N$-Boc-L-Proline $(23.42 \mathrm{~g}, 109 \mathrm{mmol})$, glycine ethyl ester hydrochloride (15.19 g, $109 \mathrm{mmol}), 1$-hydroxybenzotriazole (HOBt) monohydrate $(14.70 \mathrm{~g}, 109 \mathrm{mmol})$, triethylamine $(15.16 \mathrm{~mL}, 109 \mathrm{mmol})$ and chloroform $(117 \mathrm{~mL})$ were added at $-10{ }^{\circ} \mathrm{C}$ under nitrogen. A solution of 1-ethyl-3-(3-dimethylaminopropyl)carbodiimide (water-soluble carbodiimide, WSCI) hydrochloride (20.86 g, $109 \mathrm{mmol})$ in chloroform $(117 \mathrm{~mL}$ ) was added dropwise over $30 \mathrm{~min}$, and the resulting mixture was stirred at $-10^{\circ} \mathrm{C}$ for $30 \mathrm{~min}$ and then at $25^{\circ} \mathrm{C}$ for $24 \mathrm{~h}$. The mixture was washed sequentially with water, $5 \%$ $\mathrm{NaHCO}_{3}$ aq., and brine. The organic layer was dried with $\mathrm{Na}_{2} \mathrm{SO}_{4}$ and concentrated using a rotary evaporator. The product was dried in vacuo to give Boc-ProGly-OEt in a yield of $30.95 \mathrm{~g}$ (94\%). The obtained Boc-ProGly-OEt was then subjected to deprotection of the Boc group. To the solution of Boc-ProGly-OEt (28.0 g, $93 \mathrm{mmol})$ in dichloromethane $(84 \mathrm{~mL})$ trifluoroacetic acid $(35.46 \mathrm{~mL}, 0.46 \mathrm{~mol})$ was slowly added at $0{ }^{\circ} \mathrm{C}$ under a nitrogen atmosphere. The mixture was stirred at $0{ }^{\circ} \mathrm{C}$ for $10 \mathrm{~min}$ and then at $25{ }^{\circ} \mathrm{C}$ for $24 \mathrm{~h}$. After the solvent was removed under reduced pressure, the crude product was dissolved in dioxane/HCl (4 M, $56 \mathrm{~mL}$ ). The solution was poured into diethyl ether. The precipitate was filtered, washed with diethyl ether, and dried in vacuo to afford ProGly-OEt as a white hygroscopic solid. The yield was $17.2 \mathrm{~g}$ (92\%).

Synthesis of GlyProGly-OEt HCl salt. The proline (Pro)-containing tri-peptide GlyProGly-OEt was synthesized via a modified conventional solution method according to a previously reported procedure. ${ }^{23}$ To a flask equipped with an addition funnel and a stir bar were added $N$-Boc-Glycine (13.82 g, $78.89 \mathrm{mmol}$ ), ProGly-OEt hydrochloride (15.95 g, $78.89 \mathrm{mmol}$ ), HOBt monohydrate (10.66 g, $78.89 \mathrm{mmol})$, triethylamine (11.00 $\mathrm{mL}, 78.89 \mathrm{mmol})$ and chloroform $(80 \mathrm{~mL})$ at $-10{ }^{\circ} \mathrm{C}$ under a nitrogen atmosphere. A solution of WSCI hydrochloride (15.13 g, $78.89 \mathrm{mmol}$ ) in chloroform (80 mL) was added dropwise over $30 \mathrm{~min}$, and the resulting mixture was stirred at $-10^{\circ} \mathrm{C}$ for $30 \mathrm{~min}$ and then at $25^{\circ} \mathrm{C}$ for $24 \mathrm{~h}$. The mixture was washed sequentially with water, aq. $5 \% \mathrm{NaHCO}_{3}$ and brine. The organic layer was dried with $\mathrm{Na}_{2} \mathrm{SO}_{4}$ and concentrated using a rotary evaporator. The product was dried in vacuo to give Boc-GlyProGly-OEt in a yield of $21.35 \mathrm{~g}$ (75\%). The obtained Boc-GlyProGly-OEt was subsequently subjected to deprotection of the Boc group. To the solution of Boc- 
GlyProGly-OEt (7.08 g, $23.6 \mathrm{mmol})$ in dichloromethane $(21.0 \mathrm{~mL})$ was slowly added trifluoroacetic acid $(9.03 \mathrm{~mL}$, $118 \mathrm{mmol}$ ) at $0{ }^{\circ} \mathrm{C}$ under a nitrogen atmosphere. The mixture was stirred at $0{ }^{\circ} \mathrm{C}$ for $10 \mathrm{~min}$ and then at $25^{\circ} \mathrm{C}$ for $24 \mathrm{~h}$. After the solvent was removed under reduced pressure, the crude product was dissolved in dioxane/ $\mathrm{HCl}(4 \mathrm{M}, 14 \mathrm{~mL})$. The solution was poured into diethyl ether. The precipitate was filtered, washed with diethyl ether, and dried in vacuo to afford GlyProGly-OEt as a white hygroscopic solid. The yield was $4.78 \mathrm{~g}$ (95\%). The tri-peptide ValProGly-OEt and di-peptide ValGly-OEt were prepared using the same experimental procedure.

\section{Synthesis of poly(GlyProGly) and poly(ValGly) by} chemoenzymatic polymerization

A solution of GlyProGly-OEt hydrochloride $(1.0 \mathrm{~g}, 3.89 \mathrm{mmol})$ in phosphate buffer $(2.68 \mathrm{~mL}, 1.0 \mathrm{M}, \mathrm{pH}=8.0)$ was placed in a glass tube equipped with a stirring bar. To this solution papain (1.94 g) was added. The final concentrations of GlyProGly-OEt and papain were $1.0 \mathrm{M}$ and $50 \mathrm{mg} \mathrm{mL} \mathrm{mL}^{-1}$, respectively. The mixture was stirred at $40{ }^{\circ} \mathrm{C}$ at $800 \mathrm{rpm}$ for $2 \mathrm{~h}$ using an EYELA ChemiStation PPS-5511 instrument (Tokyo Rikakikai Co. Ltd, Tokyo, Japan). After $2 \mathrm{~h}$, the reaction mixture was cooled to room temperature; the precipitate was collected by centrifuging at $9000 \mathrm{rpm}$ and $4{ }^{\circ} \mathrm{C}$ for $30 \mathrm{~min}$. The crude product was washed twice with deionized water, centrifuged, and lyophilized to obtain poly(GlyProGly)-OEt as a white powder. The yield was $0.310 \mathrm{~g}$ (31\%). Poly(ValGly) was synthesized by chemoenzymatic polymerization using the same experimental procedure.

\section{Synthesis of poly(GlyProGly-co-ValGly) and poly(ValProGly-co- ValGly) by chemoenzymatic polymerization}

A solution of GlyProGly-OEt hydrochloride (0.3 g, $1.16 \mathrm{mmol})$ in phosphate buffer $(0.5719 \mathrm{~mL}, 1.0 \mathrm{M}, \mathrm{pH}=8.0)$ was added to ValGly-OEt $(0.2357 \mathrm{~g}, 1.16 \mathrm{mmol})$, and the resulting solution was placed in a glass tube equipped with a stirring bar. To this solution, papain $(58.30 \mathrm{mg})$ was added. The concentration of papain was $50 \mathrm{mg} \mathrm{mL}^{-1}$. The mixture was stirred at $40{ }^{\circ} \mathrm{C}$ and $800 \mathrm{rpm}$ for $2 \mathrm{~h}$ using an EYELA ChemiStation PPS-5511 instrument. After $2 \mathrm{~h}$, the reaction mixture was cooled to room temperature; the precipitate was collected by centrifuging at $9000 \mathrm{rpm}$ and $4{ }^{\circ} \mathrm{C}$ for $30 \mathrm{~min}$. The crude product was washed twice with deionized water, centrifuged, and lyophilized to obtain poly (GlyProGly-co-ValGly) as a white powder. The yield was $0.09 \mathrm{~g}$ (30\%). Poly(ValProGly-co-ValGly) was synthesized by chemoenzymatic polymerization using the same experimental procedure.

\section{Synthesis of polyPro and polyVal by chemoenzymatic} polymerization

A solution of Pro-OEt hydrochloride $(0.1 \mathrm{~g}, 0.56 \mathrm{mmol})$ in phosphate buffer $(0.43 \mathrm{~mL}, 1.0 \mathrm{M}, \mathrm{pH}=8.0)$ was polymerized by papain $(28.00 \mathrm{mg})$. The final concentrations of Pro-OEt and papain were $1.0 \mathrm{M}$ and $50 \mathrm{mg} \mathrm{mL} \mathrm{m}^{-1}$, respectively. The other reaction conditions were same as poly(GlyProGly-co-ValGly). In addition to Pro-OEt, Pro-OBn and Val-OEt were polymerized by the same method.

\section{Synthesis of poly(GlyPro) and poly(GlyPro-co-Gly) by} chemoenzymatic polymerization

A solution of GlyPro-OEt hydrochloride $(0.1 \mathrm{~g}, 0.499 \mathrm{mmol})$ in phosphate buffer $(0.374 \mathrm{~mL}, 1.0 \mathrm{M}, \mathrm{pH}=8.0)$ was polymerized by using papain $(25.00 \mathrm{mg})$. The final concentrations of GlyPro-OEt and papain were $1.0 \mathrm{M}$ and $50 \mathrm{mg} \mathrm{mL}{ }^{-1}$, respectively. The other reaction conditions and purification method were the same as for polyPro. The same experimental procedure was followed for the homopolymerization of GlyProOBn. For poly(GlyPro-co-Gly), a solution of GlyPro-OEt hydrochloride $(0.215 \mathrm{~g}, 1.074 \mathrm{mmol})$ and Gly-OEt hydrochloride $(0.150 \mathrm{~g}, 1.074 \mathrm{mmol})$ in phosphate buffer $(0.78 \mathrm{~mL}, 1.0 \mathrm{M}$, $\mathrm{pH}=8.0)$ was reacted with papain $(50.00 \mathrm{mg})$. The other reaction conditions and purification method were the same as above.

\section{Blank control reactions for chemoenzymatic polymerization}

A solution of GlyProGly-OEt hydrochloride $(1.0 \mathrm{~g}, 3.89 \mathrm{mmol})$ in phosphate buffer $(2.68 \mathrm{~mL}, 1.0 \mathrm{M}, \mathrm{pH}=8.0)$ was placed in a glass tube equipped with a stirring bar. The final concentration of GlyProGly-OEt was $1.0 \mathrm{M}$. The mixture was stirred at $40{ }^{\circ} \mathrm{C}$ and $800 \mathrm{rpm}$ for $2 \mathrm{~h}$ using an EYELA ChemiStation PPS-5511 instrument. After $2 \mathrm{~h}$, the reaction mixture was cooled to room temperature. The reaction mixture was lyophilized to obtain the crude for the ${ }^{1} \mathrm{H}$ NMR measurements, because no precipitate was observed. In addition to GlyProGlyOEt, ValGly-OEt, GlyProGly-OEt/ValGly-OEt and ValProGly-OEt/ ValGly-OEt were used for the blank control reactions.

\section{Post-polycondensation of poly(ValProGly-co-ValGly) using polyphosphoric acid (PPA)}

A solution of poly(ValProGly-co-ValGly) $(50 \mathrm{mg})$ in NMP $(1 \mathrm{~mL})$ containing lithium bromide $(0.0868 \mathrm{~g}, 1 \mathrm{mmol})$ was added to polyphosphoric acid (PPA) (0.07 g) placed in a $10 \mathrm{~mL}$ flask equipped with a stir bar and a stopcock under a nitrogen atmosphere. The solution was stirred at $120{ }^{\circ} \mathrm{C}$ for $24 \mathrm{~h}$ under nitrogen. After cooling to room temperature, the mixture was poured into water and stirred for $2 \mathrm{~h}$. The precipitate was collected by centrifugation at $9000 \mathrm{rpm}$ and $4{ }^{\circ} \mathrm{C}$ for $15 \mathrm{~min}$. The crude product was washed with water, centrifuged twice, and lyophilized to afford a brown powder (35\%).

\section{Conflicts of interest}

There are no conflicts to declare.

\section{Acknowledgements}

This work was supported by the Impulsing Paradigm Change through Disruptive Technologies Program (ImPACT) of the Japan Science and Technology Corporation (JST), the RIKEN Engineering Network, and the JSPS KAKENHI Grant Number JP17K18361. 


\section{Notes and references}

1 S. Zhang, Nat. Biotechnol., 2003, 21, 1171-1178.

2 U. Hersel, C. Dahmen and H. Kessler, Biomaterials, 2003, 24, 4385-4415.

3 H. Shin, S. Jo and A. G. Mikos, Biomaterials, 2003, 24, 4353-4364.

4 R. K. Iha, K. L. Wooley, A. M. Nyström, D. J. Burke, M. J. Kade and C. J. Hawker, Chem. Rev., 2009, 109, 56205686.

5 K. Numata and D. L. Kaplan, Adv. Drug Delivery Rev., 2010, 62, 1497-1508.

6 K. Numata, Polym. J., 2015, 47, 537-545.

7 T. Passioura and H. Suga, Chem. Commun., 2017, 53, 19311940.

8 A. D. Malay, K. Arakawa and K. Numata, PLoS One, 2017, 12, e0183397.

9 B. Brodsky and A. V. Persikov, Adv. Protein Chem., 2005, 70, 301-339.

10 S. M. Mithieux and A. S. Weiss, Adv. Protein. Chem., 2005, 70, 437-461.

11 Y. Chen and Z. Guan, J. Am. Chem. Soc., 2010, 132, 45774579.

12 R. B. Merrifield, J. Am. Chem. Soc., 1963, 85, 2149-2154.

13 I. Coin, M. Beyermann and M. Bienert, Nat. Protoc., 2007, 2, 3247-3325.

14 F. Guzman, S. Barberis and A. Illanes, Electron. J. Biotechnol., 2007, 10, 279-314.

15 K. Tsuchiya and K. Numata, Macromol. Biosci., 2017, 1700177.

16 K. Numata and P. J. Baker, Biomacromolecules, 2014, 15, 3206-3212.

17 K. Yazawa and K. Numata, Molecules, 2014, 19, 1375513774.

$18 \mathrm{~J}$. Fagerland, A. F. Wistrand and K. Numata, Biomacromolecules, 2014, 15, 735-743.
19 Y. Ma, Z. Li and K. Numata, ACS Biomater. Sci. Eng., 2016, 2, 697-706.

20 K. Tsuchiya and K. Numata, ACS Macro Lett., 2017, 6, 103106.

21 X. Qin, A. C. Khuong, Z. Yu, W. Du, J. Decatur and R. A. Gross, Chem. Commun., 2013, 49, 385-387.

22 X. Qin, W. Xie, S. Tian, J. Cai, H. Yuan, Z. Yu, G. L. Butterfoss, A. C. Khuong and R. A. Gross, Chem. Commun., 2013, 49, 4839-4841.

23 K. Tsuchiya and K. Numata, Chem. Commun., 2017, 53, 7318-7321.

24 G. Li, V. K. Raman, W. Xie and R. A. Gross, Macromolecules, 2008, 41, 7003-7012.

25 P. J. Baker and K. Numata, Biomacromolecules, 2011, 13, 947-951.

26 E. Galoppini and M. A. Fox, J. Am. Chem. Soc., 1996, 118, 2299-2300.

27 R. A. Gross, A. Kumar and B. Kalra, Chem. Rev., 2001, 101, 2097-2124.

28 S. Matsumura, Macromol. Biosci., 2002, 2, 105-126.

29 S. Shoda, H. Uyama, J. Kadokawa, S. Kimura and S. Kobayashi, Chem. Rev., 2016, 116, 2307-2413.

30 Y. Ma, R. Sato, Z. Li and K. Numata, Macromol. Biosci., 2016, 16, 151-159.

31 K. Tsuchiya and K. Numata, Macromol. Biosci., 2016, 16, 1001-1008.

32 B. Vrhoski, S. Jensen and A. S. Weiss, Eur. J. Biochem., 1997, 250, 92-98.

33 A. M. Tamburro, M. Lorusso, N. Ibris, A. Pepe and B. Bochicchio, Chirality, 2010, 22, E56-E66.

34 D. Weller, J. R. McDaniel, K. Fischer, A. Chilkoti and M. Schmidt, Macromolecules, 2013, 46, 4966-4971.

35 V. Samouillan, C. Andre, J. Dandurand and C. Lacabanne, Biomacromolecules, 2004, 5, 958-964.

36 X. Hu, X. Wang, J. Rnjak, A. S. Weiss and D. L. Kaplan, Biomaterials, 2010, 31, 8121-8131. 